\title{
Behaviour change techniques to optimise participation in physical activity or exercise in adolescents and young adults with chronic cardiorespiratory \\ conditions: a systematic review
}

\author{
Abbey Sawyer ${ }^{1,2,3}$, Hayley Lewthwaite ${ }^{4}$, Daniel F. Gucciardi ${ }^{1}$, Kylie Hill ${ }^{1,3}$, Sue Jenkins ${ }^{1,2,3}$ Vinicius $^{2}$ \\ Cavalheri ${ }^{1,3}$ \\ ${ }^{1}$ School of Physiotherapy and Exercise Science, Faculty of Health Science, Curtin University, \\ Bentley, Perth, Western Australia, Australia \\ ${ }^{2}$ Physiotherapy Department, Sir Charles Gairdner Hospital, Perth, Western Australia, Australia \\ ${ }^{3}$ Institute for Respiratory Health, Perth, Western Australia, Australia \\ ${ }^{4}$ Alliance for Research in Exercise, Nutrition and Activity, School of Health Science, University of \\ South Australia, Adelaide, South Australia, Australia
}

\section{Contact details}

Abbey Sawyer: Abbey.Sawyer@health.wa.gov.au

Hayley Lewthwaite: Hayley.Lewthwaite@mymail.unisa.edu.au

Daniel Gucciardi: D.Gucciardi@curtin.edu.au

Kylie Hill: $\underline{\text { K.Hill@curtin.edu.au }}$

Sue Jenkins: S.Jenkins@curtin.edu.au

Vinicius Cavalheri: Vinicius.Cavalheri@curtin.edu.au

\section{Corresponding author}

Name: Vinicius Cavalheri

This is the author manuscript accepted for publication and has undergone full peer review but has not been through the copyediting, typesetting, pagination and proofreading process, which may lead to differences between this version and the Version of Record. Please cite this article as doi: $10.1111 / \mathrm{imj} .14141$

This article is protected by copyright. All rights reserved. 
Address: School of Physiotherapy and Exercise Science, Faculty of Health Sciences, Curtin

University, Kent Street, Bentley, Perth, Western Australia, Australia, 6102

Email: Vinicius.Cavalheri@curtin.edu.au

\section{Funding}

No specific funding was received for this systematic review. However, this paper will form part of a $\mathrm{PhD}$ (AS), which is supported by Curtin University, and the Institute for Respiratory Health (Conquer Cystic Fibrosis Research Program), the Australian Cystic Fibrosis Research Trust (top-up scholarship) and Sir Charles Gairdner Hospital (Research Advisory Committee Grant). VC is supported by Cancer Council Western Australia Postdoctoral Research Fellowship. DG is supported by a Curtin Research Fellowship.

(Word Count: 3508).

\section{List of Figures, Tables and Appendices}

Figure 1: Search strategy and screening procedure

Figure 2: Risk of bias summary

Figure 3: Behaviour changed techniques coded within the included studies

Table 1: Intervention characteristics

Appendix 1: MEDLINE search strategy

Appendix 2: Study characteristics

Appendix 3: Risk of bias table

This article is protected by copyright. All rights reserved. 


\section{Conflict of interest}

None to report.

This article is protected by copyright. All rights reserved. 


\begin{abstract}
Participation in regular physical activity decreases the risk of developing cardiometabolic disease. However, the proportion of people who participate in the recommended amount of physical activity is low, with common barriers including competing interests and inclement weather. In people with chronic cardiorespiratory conditions, participation in physical activity is reduced further by diseasespecific barriers; time-burden of treatment and unpleasant symptoms during physical activity. Addressing these barriers during adolescence and early adulthood may promote greater physical activity participation into older age. The aim of this review was, in people aged 15 to 45 years with chronic cardiorespiratory conditions, to classify interventions aimed at optimising participation in physical activity as 'promising' or 'not promising', and categorise the behaviour change techniques (BCTs) within these interventions. Nine databases and registries were searched (October 2017) for studies that reported objective measures of physical activity before and after an intervention period. Interventions were classified as 'promising' if a between-group difference in physical activity was demonstrated. Michie et al.’s (2013) v1 Taxonomy was used to unpack the BCTs within interventions. Across the six included studies ( $\mathrm{n}=396$ participants), 19 (20\%) of 93 BCTs were described. The interventions of three studies were classified as 'promising'. The most commonly used BCTs comprised goal setting, action planning and social support. Five BCTs were solely used in 'promising' interventions. Our review demonstrated that only 20\% of BCTs have been utilised and isolated those BCTs that were used only in 'promising' physical activity interventions in adolescents and adults with chronic cardiorespiratory conditions. (Word Count: 250)
\end{abstract}

Keywords: behaviour change technique, chronic cardiorespiratory condition, physical activity, exercise, adolescent, adult. 


\section{Background}

Participation in physical activity, which may include engaging in structured exercise, is important for maintaining health and wellbeing in the general population [1]. International societies recommend that adults participate in physical activity or aerobic exercise at a moderate intensity for at least 150 minutes per week, or at a vigorous-intensity for at least 75 minutes per week [1, 2]. Adolescents are recommended to participate in at least 60 minutes of moderate-to-vigorous intensity physical activity per day [3]. Despite the numerous physical and psychosocial health benefits of physical activity, as few as $50 \%$ of adults and $10 \%$ of young people appear to meet the current recommendations for sufficient participation in physical activity [3, 4]. The reasons for insufficient participation in physical activity in the general population include competing time interests, attitudes and motivation and environmental factors such as inclement weather [5-9].

In addition to the health benefits attained by the general population, for people with chronic cardiorespiratory conditions, participation in physical activity and exercise may optimise function, improve quality of life, slow the progression of disease and enhance prognosis [10-16]. People with chronic cardiorespiratory conditions, however, participate in less physical activity than their healthy counterparts [5, 17-20]. In addition to barriers experienced by the general population, people with a chronic cardiorespiratory condition are likely to face disease-specific barriers to participation in physical activity, such as the time-burden of treatment [6] and unpleasant symptoms of breathlessness, leg muscle and general fatigue during physical activity [7, 21]. Participation in physical activity is of particular concern during 'transitional' years such as adolescence and early adulthood. During this developmental period, peer relationships, disease-stigma and an increased level of autonomy become important influencing factors to treatment adherence [22-24]. The presence of data demonstrating a positive relationship between physical activity level in early life and physical activity levels later in 
life [25-27], suggests that targeting physical activity and exercise behaviour in adolescents and young adults is likely to be important to create positive habits and assist this population throughout the aging process.

To address issues related to poor participation in physical activity, there is growing interest in the use of behaviour change techniques (BCTs), which are the active component(s) of an intervention aimed to modify existing or stimulate new behaviours [28, 29]. Michie et al [29] designed a universally applicable Taxonomy in which 93 individual BCTs are clustered into 16 common groups. This Taxonomy has been applied to research that aims to reduce total sedentary time [30], facilitate smoking cessation [31, 32] and optimise diabetes care [33]. Researchers have yet to apply the Taxonomy to understand the BCTs employed in physical activity interventions with adolescents and young adults with a chronic cardiorespiratory condition; a population who face internal (e.g. motivation and attitudes), external (e.g. competing time interests) and disease-specific barriers to physical activity and exercise $[5,6]$. The aims of this review were, in adolescents and adults with one or more chronic cardiorespiratory conditions, to; (i) classify interventions aimed at optimising participation in physical activity as either 'promising' or 'not promising', and (ii) identify and categorise BCTs described in interventions which have been classified as 'promising' and 'not promising’.

\section{Methods}

This systematic review is reported according to the Preferred Reporting Items for Systematic Reviews and Meta-Analyses (PRISMA) guidelines [34], and was prospectively registered with PROSPERO (CRD42017068892). 


\section{Eligibility criteria}

Studies were eligible for inclusion in this review if: (i) the mean age of the sample was between 15 and 45 years, (ii) all participants had a chronic cardiorespiratory condition, which could include but was not limited to asthma, cystic fibrosis (CF), interstitial lung disease, congenital heart disease or cardiovascular disease, (iii) the study design was multi-arm with at least one participant group exposed to an intervention that incorporated BCTs included in the Taxonomy (i.e. experimental group) [29] and one group acting as a control, (iv) objective measures of physical activity were collected before and after the intervention period via either wearable technology (e.g. accelerometer, inclinometers, heart rate monitors, portable metabolic monitors or step count monitors) or direct observation.

Studies were excluded if they used a cross-over or single-group design, or were published in a language other than English. Conference abstracts were excluded.

\section{Information sources and search}

Studies were identified from computerised literature searches of PEDro (Physiotherapy Evidence Database), CENTRAL, MEDLINE, CINAHL, EMBASE (via OVID) and PsychINFO databases from their inception to October, 2017. Clinical trials registries comprising ClinicalTrials.gov, the World Health Organisation (WHO) trials portal and the Australia New Zealand Clinical Trials Registry (ANZCTR) were searched in October 2017 for protocols meeting the eligibility criteria. Where eligible protocols were identified, authors were contacted to determine if the study had been published. The search strategy used for MEDLINE can be found in Appendix 1. This search strategy was adapted for use in other databases.

This article is protected by copyright. All rights reserved. 


\section{Study selection}

Two review authors (AS and HL) used the Covidence software [35] to independently screen titles, abstracts and full papers identified by the search process against eligibility criteria. Disagreement between the two authors was resolved by discussion.

\section{Data collection process}

A data extraction template was developed a priori. A single review author (AS) undertook data extraction, the results of which were confirmed by other review authors (HL and DG). Data were extracted from eligible studies in relation to the following components:

Study characteristics: title, year, sponsorship, study design, number of participant groups, betweengroup differences at baseline and sample size.

Participant characteristics: participant groups, average age, cardiorespiratory condition and eligibility criteria.

Intervention: description (verbatim), number of interventions, monitoring and duration of sessions per week, intensity of physical activity / exercise prescribed, financial assistance received for study participation, additional support and setting.

Comparator: as per intervention.

Outcomes: assessment time point, outcome measure, between-group differences.

Behaviour change techniques: extraction of BCTs from the interventions of included studies was conducted using Michie et al.’s v1 BCT Taxonomy [29]. The Taxonomy comprises 16 major 'groups' of BCTs: Goals and Planning, Feedback and Monitoring, Social Support, Shaping Knowledge, Natural Consequences, Comparison of Behaviour, Associations, Repetition and Substitution, Comparison of Outcomes, Reward and Threat, Regulation, Antecedents, Identity, Scheduled Consequences, Self-Belief and Covert Learning. Each of these groups incorporates a number of 
individual BCTs. For example, Group 1 (Goals and Planning) encompasses nine individual BCTs: goals setting (behaviour) [1.1], problem solving [1.2], goal setting (outcome) [1.3], action planning [1.4], review behaviour goals [1.5], discrepancy between current behaviour and goal [1.6], review outcome goals [1.7], behaviour contract [1.8] and commitment [1.9]. Data were extracted following completion of the BCT v1 Taxonomy online training module (AS) and reviewed for quality by another review author who is experienced in the use of this Taxonomy (DG). A comprehensive list of the BCT v1 Taxonomy groups can be found in the supplementary material of the original article [29].

\section{Risk of bias}

Risk of bias was assessed using Cochrane’s seven evidence-based domains table [36]. This tool reports on the methodological issues related to risk of bias in the following domains; 'random sequence generation' and 'allocation concealment' (selection bias), 'blinding of participants and personnel' (performance bias), 'blinding of outcome assessment' (detection bias), 'incomplete outcome data' (attrition bias), 'selective outcome reporting' (reporting bias) and 'other bias'. Studies were scored as being at a 'high', ‘unclear' or 'low' risk of bias for each domain.

\section{Data synthesis}

\section{Classification of interventions}

Interventions were categorised as having a 'promising' or 'not promising' influence on the level of participation in physical activity in adolescents and adults with chronic cardiorespiratory conditions. Interventions were classified as 'promising' if, following the intervention period, there was a significant between-group increase in physical activity or exercise levels in favour of the experimental group. Interventions were classified as 'not promising' if, following the intervention period, no significant between-group differences were reported for physical activity or exercise levels [30, 37]. 


\section{Identification and categorisation of behaviour change techniques}

Specific components of each intervention were 'coded' as BCTs if sufficient detail was provided to validate the presence of the particular BCT on a target behaviour(s) and population(s). The BCT was labelled with '++' if the authors were confident 'beyond reasonable doubt' that the BCT was present. If the BCT appeared to be present 'in all probability' from intervention description, but there was insufficient detail, the BCT was coded as '+' [29]. For example, in one study, "Patients in the intervention group were called several times during the first 6 months of the study to check on their activity behaviour and, if necessary, to offer additional help” [38] was coded as social support (unspecified) with partial confidence ('+') because there was insufficient detail pertaining to the content of the conversation of the phone support. All 93 individual BCTs were considered for each of the interventions of the included studies. The BCTs were summarised by number and type.

\section{Results}

The search of electronic databases yielded a total of 7,692 records, of which 1,116 were duplicates. The titles and abstracts of remaining records $(n=6,576)$ were screened against eligibility criteria. Following removal of ineligible records $(n=6,428)$, full texts of remaining studies were screened for eligibility. The main reasons for exclusion following full-text review were related to no objective measure of physical activity $(n=29)$ and the mean age of participants $>45$ or $<15$ years $(n=104)$ (Figure 1).

This article is protected by copyright. All rights reserved. 


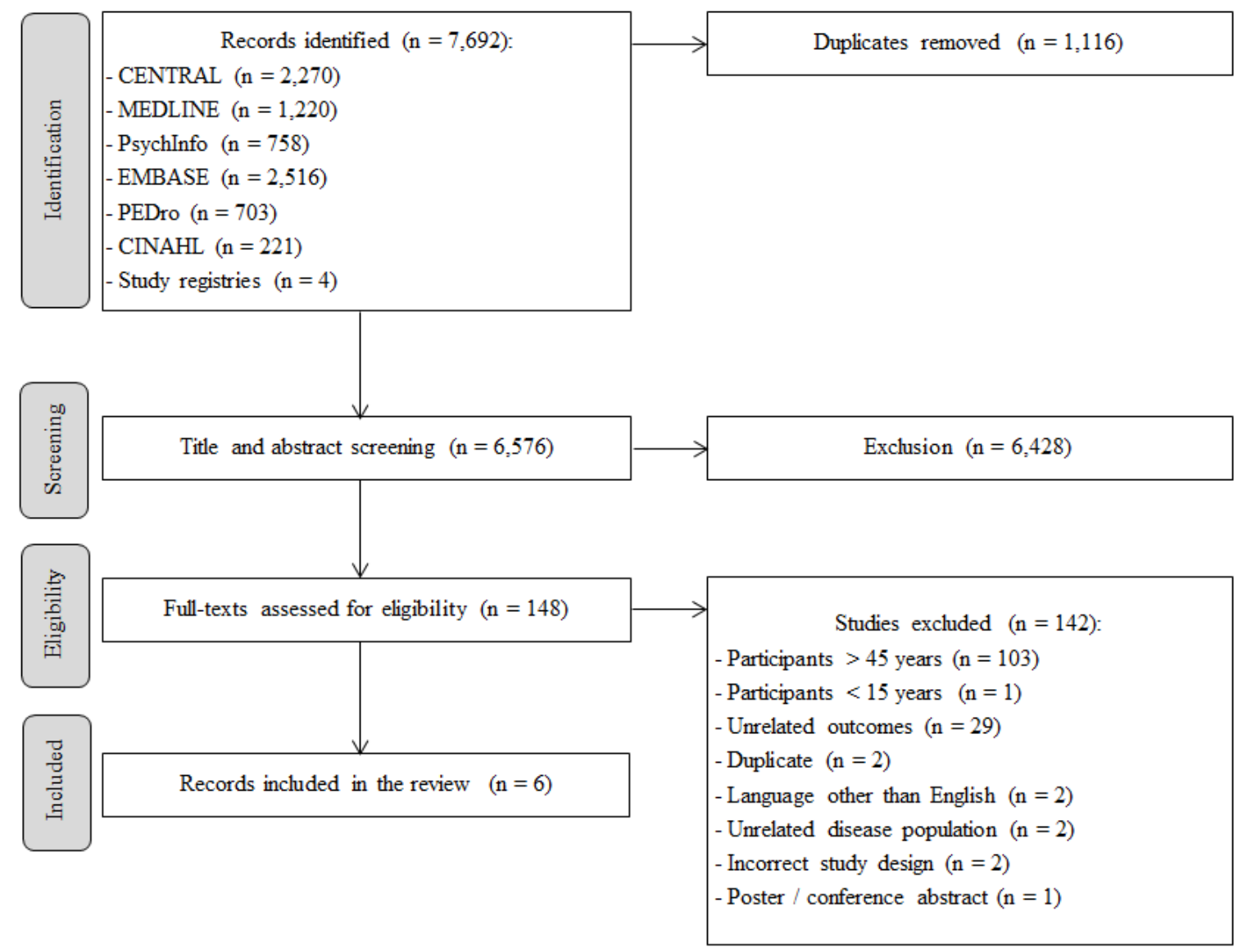

Figure 1. Search strategy and screening procedure

\section{Characteristics of included studies}

All six included studies were randomised controlled trials (RCTs), conducted in Brazil [39], the Netherlands [40], Germany [38], Switzerland and Germany [41], Ireland [42], or Australia [43]. Across the included studies, there were 396 participants aged (mean \pm SD) $15 \pm 3$ years to $45 \pm 12$ years. Sample sizes ranged from 37 to143 participants, with 183 (46\%) being female. Studies included people with asthma $(n=2)$ [39, 43], CF $(n=2)$ [38, 41], and congenital heart disease $(n=2)[40,42]$. Further study characteristics are presented in Appendix 2. 


\section{Risk of bias}

The quality of included studies was poor to fair (Figure 2). No two studies were identical in terms of the risk of bias assessment. Performance bias (blinding of participants and personnel) was high across all studies and only one study was rated as having a low risk of detection bias (blinding of outcome assessor). Intention-to-treat analysis was reported in three studies [39, 41, 42]. Three studies reported not reaching the required sample size [38, 42, 43].

This article is protected by copyright. All rights reserved. 


\begin{tabular}{|c|c|c|c|c|c|c|c|c|}
\hline & 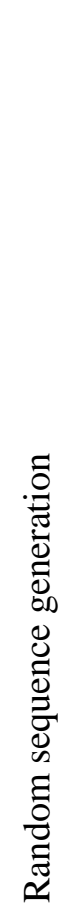 & 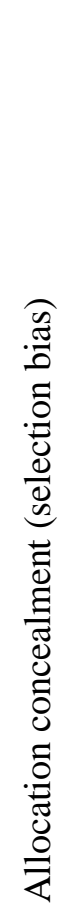 & 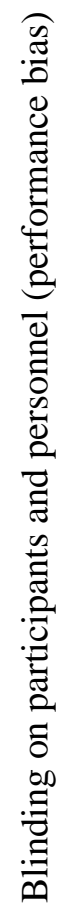 & 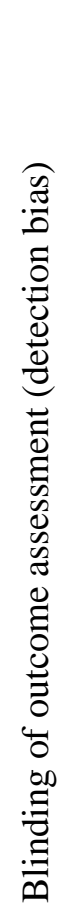 & 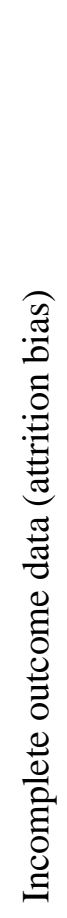 & 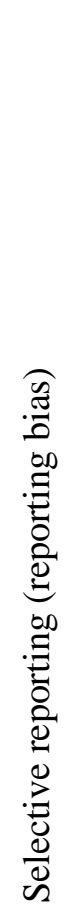 & $\frac{\bar{d}}{\tilde{D}}$ & 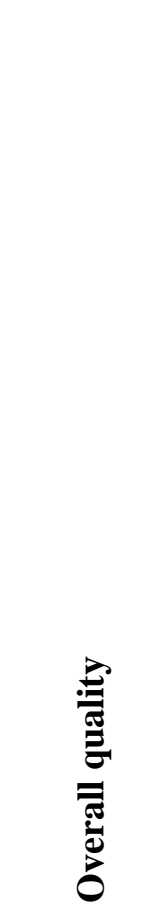 \\
\hline Coelho (2017)* [39] & + & + & - & - & + & + & + & Moderate \\
\hline Duppen (2015) [40] & ? & ? & - & - & + & + & ? & Fair \\
\hline Hebestreit (2010)* [38] & - & ? & - & - & ? & ? & ? & Poor \\
\hline Kriemler (2013) [41] & - & - & - & + & + & - & ? & Fair \\
\hline Morrison (2013)* [42] & - & - & - & - & - & - & ? & Poor \\
\hline Scott (2013) [43] & + & + & - & - & + & - & ? & Fair \\
\hline
\end{tabular}

Figure 2: Risk of bias summary

(+) Low risk of bias; (?) unclear risk of bias; (-) high risk of bias. '*' = 'promising' studies. Quality assessment; high $=6-7$ criteria met, moderate $4-5$ criteria met, fair $=2-3$ criteria met, poor $=1$ or less criteria met.

\section{Interventions}

Intervention delivery was highly variable in terms of frequency and duration of contact, supervision provided, monitoring, intensity of the physical activity and/or exercise prescribed, support provided,

This article is protected by copyright. All rights reserved. 
location and length of the intervention period (Table 1). Five studies implemented exercise training programs [38, 40-43]. In three of these studies [38, 42, 43], promotion of physical activity was added to the exercise training program. One study focussed on promotion of physical activity without an exercise training component [39]. The duration of interventions ranged from 10 weeks to 6 months. Interventions were supervised $(n=3)$ [40, 41, 43], unsupervised $(n=1)$ [39] or partially-supervised (n $=$ ) $[38,42]$. In one of the partially supervised interventions [38], participants were asked to increase their participation in a sport of their choosing by three hours each week. For example, some participants undertook resistance training in a fitness centre (supervised), other participants opted to complete independent endurance sports (cycling, jogging or swimming), and some chose to complete a mixture of these options. In the other partially-supervised intervention [42], participants undertook group education sessions, but were provided with an independent program to complete at home to increase their activity.

Four of the six included studies had a two-arm design (i.e. intervention and control group) [38-40, 42]. One study had a three-arm design (i.e. two intervention groups and a control group) [41] and one study had a four-arm design (i.e. three intervention groups and a control group) [43]. 


\begin{tabular}{|c|c|c|c|c|c|c|}
\hline & $\begin{array}{l}\text { register asthma } \\
\text { exacerbations. }\end{array}$ & & & & & $\begin{array}{l}\text { completed exercise } \\
\text { and diet intervention. }\end{array}$ \\
\hline $\begin{array}{l}\text { Duration of the } \\
\text { intervention period }\end{array}$ & 12 weeks & 12 weeks & 6 months & 6 months & 6 months & 10 weeks \\
\hline Time & $\begin{array}{l}\text { Both groups: } 1 \text { hour } \\
\text { standardised education } \\
\text { sessions. } \\
\text { Intervention group: } \\
\text { advised to increase } \\
\text { physical activity to } 5 \\
\text { times per week for }> \\
30 \text { minutes. } \\
\text { Control group: advised } \\
\text { to increase physical } \\
\text { activity to } 5 \text { times per } \\
\text { week for }>30 \text { minutes. }\end{array}$ & $\begin{array}{l}\text { Intervention group: } 3 \\
\text { times per week for } 1 \\
\text { hour. } \\
\text { Control group: no } \\
\text { change / specific time } \\
\text { commitment. }\end{array}$ & $\begin{array}{l}\text { Intervention group: } 3 \\
\text { times per week for } 1 \\
\text { hour. } \\
\text { Control group: no } \\
\text { change / specific time } \\
\text { commitment. }\end{array}$ & $\begin{array}{l}\text { Intervention groups: } 3 \\
\text { times per week for } 30 \\
\text { to } 45 \text { minutes for the } \\
\text { first } 6 \text { months of the } \\
\text { study. } \\
\text { Control group: no } \\
\text { change / specific time } \\
\text { commitment. }\end{array}$ & $\begin{array}{l}\text { Intervention group: An } \\
\text { education session and } \\
\text { follow up letter } \\
\text { summarising } \\
\text { discussions. Monthly } \\
\text { follow-up. } \\
\text { Control group: no } \\
\text { change / specific time } \\
\text { commitment. }\end{array}$ & $\begin{array}{l}\text { Intervention group (1 } \\
\text { and 3): 1-hour } \\
\text { personal training } \\
\text { session, gym } \\
\text { membership / program } \\
\text { and daily step goal. } \\
\text { Intervention group (2): } \\
\text { ('control') seven 1 } \\
\text { hour clinic visits and } \\
\text { four } 10 \text { minute phone } \\
\text { calls with a dietician. }\end{array}$ \\
\hline $\begin{array}{l}\text { Intensity of } \\
\text { intervention }\end{array}$ & $\begin{array}{l}\text { Each participant asked } \\
\text { to commence walking } \\
\text { at a moderate intensity } \\
\text { (talk test - explain } \\
\text { this). Progressive } \\
\text { step-based goals. }\end{array}$ & $\begin{array}{l}10 \text { minute warm up } \\
\text { and cool down. } 40 \\
\text { minutes of aerobic } \\
\text { exercise at } 60 \text { to } 70 \% \\
\text { maximal heart rate. }\end{array}$ & $\begin{array}{c}\text { Below gas exchange } \\
\text { threshold (equivalent } \\
\text { heart rate). }\end{array}$ & $\begin{array}{c}\text { Strength training: set } \\
\text { by fitness centre staff. } \\
\text { Weight increase by } 5 \% \\
\text { per week if the } \\
\text { participant could do > } \\
9 \text { repetitions. } \\
\text { Anaerobic training: } \\
\text { commenced at } 65 \% \\
\mathrm{VO}_{2 \text { peak. }}\end{array}$ & Not specified. & Not specified. \\
\hline
\end{tabular}




\begin{tabular}{|c|c|c|c|c|c|}
\hline Location & $\begin{array}{c}\text { Community-based } / \\
\text { independent. }\end{array}$ & Not specified. & $\begin{array}{c}\text { Variable (i.e. fitness } \\
\text { centre or sports club) }\end{array}$ & $\begin{array}{c}\text { Fitness centre (both } \\
\text { intervention groups) or } \\
\text { home (anaerobic } \\
\text { training only). }\end{array}$ & $\begin{array}{c}\text { Home / community- } \\
\text { based. }\end{array}$ \\
\hline
\end{tabular}

Abbreviations: $\mathrm{VO}_{2 \text { peak: }}$ peak rate of oxygen uptake. 


\section{Interventions considered promising versus not promising (aim 1)}

Of the six included studies [38-43], half $(\mathrm{n}=3)$ [38, 39, 42] were considered to have a 'promising' effect of physical activity or participation in exercise.

\section{Behaviour change techniques across all studies (aim 2)}

Nineteen (20\%) of the 93 individual BCTs outlined in the v1 Taxonomy were represented within the study interventions (Figure 3). The number of individual BCTs identified within each of the included studies ranged from two [40] to 10 [41], with (mean \pm SD) $6 \pm 3$ BCTs described per study. The most commonly used BCTs across included studies were goal setting (behaviour) [indicated in Figure 3 as 1.1] (5/6 studies) and action planning [indicated in Figure 3 as 1.4] (5/6 studies). Eight BCTs were coded only once across the six studies; problem solving [indicated in Figure 3 as 1.2], goal setting (outcome) [indicated in Figure 3 as 1.3], feedback on behaviour [indicated in Figure 3 as 2.2], information about health consequences [indicated in Figure 3 as 5.1], credible source [indicated in Figure 3 as 9.1], pros and cons [indicated in Figure 3 as 9.2], comparative imagining of future outcomes [indicated in Figure 3 as 9.3] and adding objects to the environment [indicated in Figure 3 as 12.5].

Behaviour change techniques used in promising interventions

The most frequently used BCTs in interventions categorised as having a 'promising' effect on physical activity or participation in exercise were goal setting (behaviour) [indicated in Figure 3 as 1.1] and action planning [indicated in Figure 3 as 1.4]. Each of these BCTs were utilised on four occasions across three separate interventions [38, 39, 42]. Five BCTs were solely used in 'promising' interventions; problem solving [indicated in Figure 3 as 1.2], information about antecedents [indicated in Figure 3 as 4.2], information about health consequences [indicated in Figure 3 as 5.1], pros and cons [indicated in Figure 3 as 9.2] and comparative imagining of future outcomes [indicated in Figure

This article is protected by copyright. All rights reserved. 
3 as 9.2]. Of the 24 occasions BCTs were used in 'promising' interventions, 22 were described in sufficient detail to validate their presence with complete confidence [++, 'beyond reasonable doubt']).

\section{Behaviour change techniques used in not promising interventions}

The most commonly coded BCTs amongst interventions with a 'not promising' effect on physical activity or participation in exercise was goal setting (behaviour) [indicated in Figure 3 as 1.1], which was identified and coded on four occasions by four interventions [41, 43]. On one of these occasions, the BCT could only be coded with partial confidence (+, 'in all probability) [43]. Goal setting (outcome) [indicated in Figure 3 as 1.3], feedback on behaviour [indicated in Figure 3 as 2.2], credible source [indicated in Figure 3 as 9.1] and adding objects to the environment [indicated in Figure 3 as 12.5] were used only in 'not promising' interventions. Of the 27 occasions BCTs were used in 'not promising' interventions, 22 were described in sufficient detail to validate their presence with complete confidence [++, 'beyond reasonable doubt].

This article is protected by copyright. All rights reserved. 


\begin{tabular}{|c|c|c|c|c|c|c|c|}
\hline Group & BCT identified & 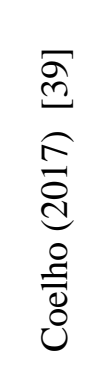 & 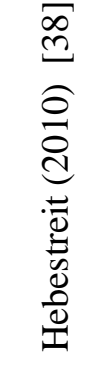 & 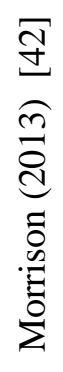 & 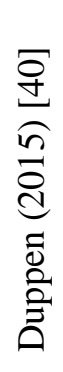 & 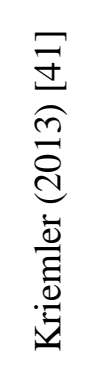 & 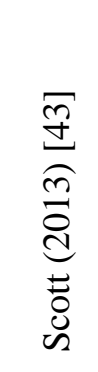 \\
\hline Group 1: Goals and Planning & Goal setting (behaviour) (1.1) & $2++$ & & ${ }^{++}$ & & $2++$ & $2++/+$ \\
\hline Group 1: Goals and Planning & Problem solving (1.2) & & & + & & & \\
\hline Group 1: Goals and Planning & Goal setting (outcome) (1.3) & & & & & & + \\
\hline Group 1: Goals and Planning & Action planning (1.4) & ++ & $2++$ & ${ }^{++}$ & & $2++$ & ${ }^{++}$ \\
\hline Group 1: Goals and Planning & Review behaviour goal (1.5) & ++ & & & & $2++$ & \\
\hline Group 2: Feedback and Monitoring & Self-monitoring of behaviour (2.3) & ++ & & & & & $2++$ \\
\hline Group 2: Feedback and Monitoring & Biofeedback (2.6) & & ++ & & ++ & ${ }^{++}$ & \\
\hline Group 3: Social Support & Social support (unspecified) (3.1) & & $2++/+$ & ${ }^{++}$ & & $\ldots$ & + \\
\hline Group 3: Social Support & Social support (practical) (3.2) & & $2++$ & & & $2++$ & + \\
\hline Group 4: Shaping Knowledge & Instruction on how to perform a behaviour (4.1) & & ++ & & ++ & ${ }^{++}$ & \\
\hline
\end{tabular}

This article is protected by copyright. All rights reserved. 


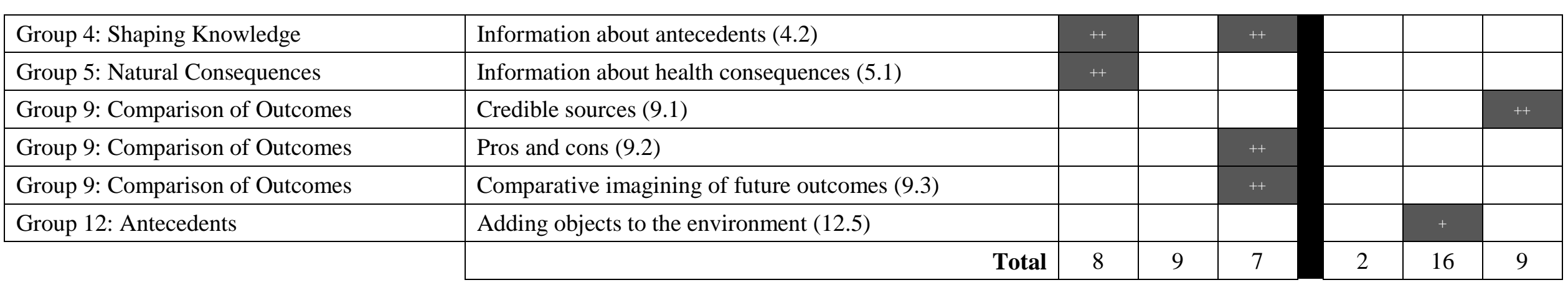

Figure 3: BCTs coded within the included studies

BCT coded once within the study. BCT coded more than once within the study (the number in the box indicates number of occasions that the BCT was used) '*' next to the author's name indicates that intervention within the study was categorised as 'promising'. A ' ++ ' next to the BCT indicates that reviewers were confident 'beyond reasonable doubt' that the technique was present. A '+' next to the BCT indicates that the technique was present 'in all probability', however, supporting information was lacking.

This article is protected by copyright. All rights reserved. 


\section{Discussion}

This systematic review is the first to apply the BCT v1 Taxonomy [29] to interventions aimed at optimising physical activity, which may have included participation in exercise, in adolescents and younger adults with chronic cardiorespiratory conditions. Six studies met our inclusion criteria and were of fair to poor quality. The three main findings of this systematic review were that: (i) only $20 \%$ of the individual BCTs outlined in the v1 Taxonomy were represented within the interventions of included studies, (ii) three of the six studies had interventions that had a 'promising' influence on physical activity or participation in exercise, and (iii) five BCTs (namely problem solving, information about antecedents, information about health consequences, pros and cons, and comparative imagining of future outcomes) were solely used in 'promising' interventions.

The finding that few (20\%) of the BCTs outlined in the v1 Taxonomy [29] were represented within the interventions of included studies support earlier work which report a limited number of BCTs in studies aiming to optimise physical activity or implement home-based cardiac rehabilitation in adults with chronic obstructive pulmonary disease (COPD) [44] and cardiac disease [45], respectively. A recent systematic review on the use of BCTs by physiotherapists in interventions aimed at increasing physical activity has demonstrated that 'promising' interventions used more BCTs than 'not promising' interventions [46]. This finding contrasts with our work, which identified a comparable number of BCTs between the interventions of 'promising' and 'not promising' studies. One possible reason for this disparity is that our study only included RCTs and the decision to classify interventions as 'promising' was the finding of significant between-group differences in objective measures of physical activity. In contrast, the earlier systematic review [46] included studies that provided lower levels of evidence (i.e. uncontrolled single-group studies with subjectively reported measures of physical activity). 
Commonly used BCTs were similar between ‘promising' and ‘not promising' interventions and included goal setting (behaviour) and action planning. Goal setting (behaviour) is defined as 'setting or agreeing on a goal defined in terms of the behaviour to be achieved, for example, agreeing on a weekly exercise target’ [29]. Action planning is similar except that in addition to defining a goal, explicit instruction is given regarding the context, frequency, duration and/or intensity of the behaviour. Of note, action planning was used in all of the 'promising' studies, and two of the three non-promising studies. Notwithstanding these similarities in BCTs common to 'promising' and 'not promising' interventions, there were two noticeable differences in the way they were applied: (i) specificity of the goal (i.e. promotion of physical activity rather than just participation in the exercise program) and (ii) length of intervention. That is, compared to 'not promising' interventions, which tended to focus solely on an exercise program, 'promising' interventions included promotion of physical activity either alone [39] or in combination with an exercise program [38, 42]. For example, Morrison et al [42] discussed ways to increase physical activity, and in the study by Hebestreit et al [38], physical activity counselling and discussion of an activity plan were undertaken. Our data suggest that when attempting to increase participation in physical activity, it is the embedding of specific instructions regarding the execution of this health behaviour (i.e. action planning) within an exercise training intervention that is needed to optimise success [47]. Additionally, the current study demonstrated that longer interventions seem to be more advantageous than shorter interventions to change physical activity behaviour in adolescents and adults with a chronic cardiorespiratory condition. That is, the majority of 'promising' interventions (2/3) were 6 months or longer in length, compared to an average of 12 weeks or less for the majority (2/3) of 'not promising' interventions. This finding is in agreement with results of a study of pulmonary rehabilitation in people with COPD that demonstrated that a 3-month intervention improved exercise capacity, muscle force and quality of life. However, physical activity only improved after six months of intervention [48]. The reason that 
longer interventions appear to be advantageous compared to shorter interventions may be due to the time it takes to implement physical activity BCTs and/or the time is takes for these BCTs to positively influence the target behaviour.

Several BCTs were described only within ‘promising' interventions. Specifically, problem solving, which is categorised within the Goals and Planning group of the BCT v1 Taxonomy [29], was solely used in 'promising' interventions and suggests that when attempting to change physical activity, it is important to offer problem solving together with goal setting (behaviour) and action planning. Given the magnitude of barriers for people with chronic cardiorespiratory conditions, identifying obstacles and potential solutions in advance is important for ongoing adherence to physical activity and exercise programs. Earlier work has also reported the value of highlighting behavioural 'norms' to participants, particularly in the context of goal setting $[49,50]$, and this is likely to explain why information about antecedents and information about health consequences were identified within 'promising' interventions. Another BCT used only in 'promising' interventions was pros and cons, whereby 'a person is advised to identify and compare reasons for wanting (pro) or not wanting (con) to change a behaviour' [29]. This technique, commonly referred to in the literature as decisional balance, is an important element of behaviour adoption [51] and positive decisional balance (i.e. higher perceived pros than cons) has been shown to strongly influence the participation in physical activity [52]. Additionally, positive decisional balance may have a role in long term participation in physical activity in people who are already active [53]. Finally, comparative imagining of future outcomes, or mental contrasting, was also used solely in 'promising' interventions. Similar to decisional balance, this technique emphasises the need for action upon a goal through consideration of a positive future achievement of a behaviour (e.g. completing physical activity 30 minutes per day) with negative barriers (e.g. motivation, inclement weather, competing time interests) and is particularly useful in adolescents and adults [54, 55]. Our finding that these BCTs were described in 'promising' 
interventions is supported by earlier work. For example, in a systematic review investigating the use of BCTs in cardiac rehabilitation programmes [45], information about health consequences was only used by efficacious cardiac rehabilitation programmes. Likewise, in another review investigating BCTs utilised by physiotherapists for physical activity interventions in people with noncommunicable disease, problem solving and information about health consequences were only identified in interventions considered efficacious at improving physical activity [46].

Although this review used a comprehensive search strategy to find studies that met our eligibility criteria, the results should be interpreted with caution as the number of studies included was small and their quality was variable. Further, on several occasions, we were unable to code potential BCTs with any confidence due to insufficient detail reported for the intervention. The breadth of uncoded BCTs, techniques only coded on a single occasion, and the heterogeneity and limited number of included studies reduces our confidence to conclude which BCTs are likely to be most useful to optimise physical activity in adolescents and adults with chronic cardiorespiratory conditions. This uncertainty highlights the underdevelopment of the evidence-base in this area. It is the authors' hope that the use of the BCT v1 Taxonomy [29] in this paper will prompt others to report the active components of an intervention with clarity and consistency to facilitate meaningful future research, as well as the translation of efficacious interventions into clinical practice. Moreover, studies were only included in the review if the measurement of physical activity was device-based or by direct observation. While device-based measures of physical activity are more robust than self-reported measures of physical activity [56], studies aiming to optimise physical activity or participation in exercise which utilised subjective measures of physical activity may have included BCTs which have not been used in the studies included in the current review. 


\section{Conclusion}

A relatively small number of potential BCTs were identified within interventions aiming to optimise physical activity in adolescents and adults with a chronic cardiorespiratory condition. Although there was some overlap in the BCTs described within 'promising' and 'not promising' interventions, BCTs such as problem solving, information about antecedents, information about health consequences, pros and cons and comparative imagining of future outcomes were only used in those studies which reported 'promising' interventions. Despite the growing consensus surrounding the importance of BCTs to change health behaviours, this systematic review has demonstrated that details of specific interventional BCTs may be underreported, or BCTs may not be considered fully when devising an intervention in adolescents and adults with a chronic cardiorespiratory condition. At present, there is limited evidence to support the use of individual BCTs, or specific combinations of BCTs over others within interventions aiming to optimise physical activity in this population. However, the findings of the current review suggest that 'promising' interventions may have to incorporate a combination of exercise program and the specific promotion of physical activity and were offered over a duration of at least 6 months.

This article is protected by copyright. All rights reserved. 


\section{References}

1. World Health Organisation. 2010. Global Recommendations on Physical Activity for Health.

2. Garber CE, Blissmer B, Deschenes MR, Franklin BA, Lamonte MJ, Lee IM et al. Quantity and quality of exercise for developing and maintaining cardiorespiratory, musculoskeletal, and neuromotor fitness in apparently healthy adults: guidance for prescribing exercise. Med Sci Sports Exerc. 2011; 43(7):1334-1359. doi:10.1249/MSS.0b013e318213fefb.

3. Australian Beaueau of Statistics. 2013. Australian Health Survey: Physical Activity $2011-12$.

4. Sallis JF, Cerin E, Conway TL, Adams MA, Frank LD, Pratt M. Physical activity in relation to urban environments in 14 cities worldwide: a cross-sectional study. The Lancet. 2016; 387(10034): 2207-2217.

5. White D, Stiller K, Haensel N. Adherence of adult cystic fibrosis patients with airway clearance and exercise regimens. J Cyst Fibros. 2007;6(3):163-170.

6. Sawicki GS, Sellers DE, Robinson WM. High treatment burden in adults with cystic fibrosis: challenges to disease self-management. J Cyst Fibros. 2009;8(2):91-96.

7. Thorpe OK, Johnston K \& Kumar S. Barriers and enablers to physical activity participation in patients with COPD: a systematic review. J Cardiopulm Rehabil Prev. 2012; 32(6): 359-69.

8. Boyle MP. So many drugs, so little time: the future challenge of cystic fibrosis care. Chest. 2003;123(1):3-5.

9. Granger CL, Connolly B, Denehy L, Hart N, Antippa P, Lin KY et al. Understanding factors influencing physical activity and exercise in lung cancer: a systematic review. Support Care Cancer. 2017; 25(3): 983-999.

10. Pianosi P, Leblanc J, Almudevar A. Peak oxygen uptake and mortality in children with cystic fibrosis. Thorax. 2005;60(1):50-54.

11. Nixon PA, Orenstein DM, Kelsey SF, Doershuk CF. The prognostic value of exercise testing in patients with cystic fibrosis. N Engl J Med. 1992;327(25):1785-1788.

12. Hebestreit H, Schmid K, Kieser S, Junge S, Ballmann M, Roth K, Hebestreit A, Schenk T, Schindler C, Posselt HG, Kriemler S. Quality of life is associated with physical activity and fitness in cystic fibrosis. BMC Pulmonary Medicine. 2014; 14:26.

13. Eijkemans M, Mommers M, Draaisma JMT, Thijs C, Prins MH.Physical Activity and Asthma: A Systematic Review and Meta-Analysis. PLOS ONE. 2012; 7(12): p.50775.

14. Turner S, Eastwood P, Cook A. Jenkins S. Improvements in symptoms and quality of life following exercise training in older adults with moderate/severe persistent asthma.

Respiration. 2011; 81(4): 302-10.

15. Diller GP \& Baumgartner H. Sudden cardiac death during exercise in patients with congenital heart disease: The exercise paradox and the challenge of appropriate counselling. Eur Heart J. 2016; 37(7): 627-629.

16. Giardini A, Specchia S, Tacy TA, Coutsoumbas G, Gargiulo G, Donti A et al. Usefulness of cardiopulmonary exercise to predict long-term prognosis in adults with repaired tetralogy of fallot. Am J Cardiol. 2007; 99(10): 1462-1467.

17. Longmuir PE, Brothers JA, de Ferranti SD, Hayman LL, Van Hare GF, Matherne GP et al. Promotion of physical activity for children and adults with congenital heart disease. A scientific statement from the American Heart Association. 2013; 127(21): 2147-2159.

18. Dua JS, Cooper AR, Fox KR, Graham SA. Physical activity levels in adults with congenital heart disease. Eur J Cardiovasc Prev Rehabil. 2007; 14(2): 287-93.

19. Lunt D, Briffa T, Briffa NK, Ramsay J. Physical activity levels of adolescents with congenital heart disease. Aust J Physiother. 2003; 49(1): 43-50. 
20. Vorrink SN, Kort HS, Troosters T, Lammers JW. Level of daily physical activity in individuals with COPD compared with healthy controls. Respir Res. 2011; 12: 33.

21. Kosteli MC, Heneghan NR, Roskell C, Williams SE, Adab P, Dickens AP et al. Barriers and enablers of physical activity engagement for patients with COPD in primary care. Int J Chron Obstruct Pulmon Dis. 2017;12:1019-1031.

22. Shakkottai A, Kidwell KM, Townsend M, Nasr SZ. A five-year retrospective analysis of adherence in cystic fibrosis. Pediatr Pulmonol. 2015; 50(12): 1224-1229.

23. Quittner AL. Zhang J, Marynchenko M. Chopra PA, Signorovitch J. Yushkina Y et al. Pulmonary medication adherence and health-care use in cystic fibrosis. Chest. 2014. 146(1): 142-151.

24. Jack K.McLean, SM, Moffett JK, Gardiner E. Barriers to treatment adherence in adolescents with cystic fibrosis: A mixed-methods analysis. Man Ther. 2010; 15(3): 220-228.

25. Telama R, Yang X.Viikari J, Valimaki I.Wanne O.Raitakari O. Physical activity from childhood to adulthood: a 21-year tracking study. Am J Prev Med. 2005; 28(3): 267-73.

26. Matton L, Thomis M, Wijndaele K, Duvigneaud N, Beunen G, Claessens A et al. Tracking of physical fitness and physical activity from youth to adulthood in females. Med Sci Sports Exerc. 2006; 38(6): 1114-20.

27. Tammelin T, Nayha S, Hills AP, Jarvelin MR. Adolescent participation in sports and adult physical activity. Am J Prev Med. 2003; 24(1): 22-8.

28. Abraham C \& Michie S. A taxonomy of behavior change techniques used in interventions. Health Psychol. 2008;27(3):379-87.

29. Michie S, Richardson M, Johnston M, Abraham C, Francis J, Hardeman W, Eccles MP, Cane J, Wood CE. The behavior change technique taxonomy (v1) of 93 hierarchically clustered techniques: building an international consensus for the reporting of behavior change interventions. Ann Behav Med.2013;46(1):81-95.

30. Gardner B, Smith L, Lorencatto F, Hamer, M, Biddle SJH. How to reduce sitting time? A review of behaviour change strategies used in sedentary behaviour reduction interventions among adults. Health Psych Rev. 2016;10(1):89-112.

31. West R, Walia A, Hyder N, Shahab L, Michie S. Behavior change techniques used by the English Stop Smoking Services and their associations with short-term quit outcomes. Nicotine Tob Res. 2010;12(7):742-747.

32. Michie S, Hyder N, Walia A, West R. Development of a taxonomy of behaviour change techniques used in individual behavioural support for smoking cessation. Addict Behav. 2011;36(4):315-319.

33. Presseau J, Ivers NM, Newham JJ, Knittle K, Danko KJ, Grimshaw JM. Using a behaviour change techniques taxonomy to identify active ingredients within trials of implementation interventions for diabetes care. Implement Sci. 2015;10(1):55.

34. Moher D, Liberati A, Tetzlaff J, Altman DG.Preferred reporting items for systematic reviews and meta-analyses: the PRISMA statement. PLoS medicine. 2009;6(7):1549-1676.

35. Covidence systematic review software. Melbourne, Australlia. Veritas Health Innoation. Available at www.covidence.org

36. Higgins JPT, Altman DG, Gøtzsche PC, Jüni P, Moher D, Oxman AD, Savović J, Schulz KF, Weeks L, Sterne JAC. The Cochrane Collaboration's tool for assessing risk of bias in randomised trials. Biomed J. 2011;343.

37. Willett M, Duda J, Gaunrey C, Fenton S, Greig C, Rushton A. Effectiveness of behavioural change techniques in physiotherapy interventions to promote physical activity adherence in patients with hip and knee osteoarthritis: a systematic review protocol. Biomed J Open. 2017;7(6). 
38. Hebestreit H, Kieser S, Junge $\mathrm{S}$ et al. Long-term effects of a partially supervised conditioning programme in cystic fibrosis. Eur Respir J. 2010; 35(3):578-83.

doi:10.1183/09031936.00062409.

39. Coelho CM, Reboredo MM, Valle FM, Malaguti C, Campos LA, Nascimento LM et al. Effects of an unsupervised pedometer-based physical activity program on daily steps of adults with moderate to severe asthma: a randomized controlled trial. J Sports Sci. 2017; 36(10): 1186-1193.

40. Duppen N, Etnel JR, Spaans L, Takken T, van den Berg-Emons RJ, Boersma E et al. Does exercise training improve cardio-respiratory fitness and daily physical activity in adolescents with corrected tetralogy of Fallot or Fontan circulation? A randomized controlled trial. Am Heart J. 2015; 170(3): 606-14.

41. Kriemler S, Kieser S, Sibylle J, Ballmann M, Hebestreit A, Schindler C et al. Effect of supervised training on FEV1 in cystic fibrosis: a randomised controlled trial. J Cyst Fibros. 2013; 12 (6): 714-720.

42. Morrison MI, Sands AJ, McCusker CG, McKeown PP, McMahon M, Gordon J et al. Exercise training improves activity in adolescents with congenital heart disease. Heart. 2013; 15: 11221128.

43. Scott HA, Gibson PG, Garg MI, Pretto JJ, Morgan PJ, Callister R et al. Dietary restriction and exercise improve airway inflammation and clinical outcomes in overweight and obese asthma: a randomized trial. Clin Exper Allergy. 2013; 43(1): 36-49.

44. Wilson JJ, O’Neill B, Collins EG, Bradley J. Interventions to Increase Physical Activity in Patients with COPD: A Comprehensive Review. J COPD. 2015; 12(3): 339-354.

45. Heron N, Kee F, Donnelly M, Cardwell C, Tully MA, Cupples ME. Behaviour change techniques in home-based cardiac rehabilitation: a systematic review. Br J Gen Pract. 2016: 66(651): e747-e757. http://doi.org/10.3399/bjgp16X686617.

46. Kunstler BE, Cook JL, Freene N, Finch CF, Kemp JL, O’Halloran PD et al. Physiotherapists use a small number of behaviour change techniques when promoting physical activity: A systematic review comparing experimental and observational studies. J Sci Med Sport. 2018; 21(6):609-615.

47. Carraro N \& Gaudreau P. Spontaneous and experimentally induced action planning and coping planning for physical activity: A meta-analysis.Psychol Spor Exerc. 2013; 14(2): 228248.

48. Pitta F, Troosters T, Probst VS, Langer D, Decramer M, Gosselink R.Are patients with COPD more active after pulmonary rehabilitation? Chest. 2008; 134(2): 273-280.

49. McEwan D, Harden SM, Zumbo BD, Sylvester BD, Kaulius M, Ruissen GR et al. The effectiveness of multi-component goal setting interventions for changing physical activity behaviour: a systematic review and meta-analysis. Health Psychol Rev. 2016; 10(1): 67-88.

50. Latham GP \& Locke EA. Self-regulation through goal setting. Organ Behav Hum Decis Process. 1991; 50(2): 212-247.

51. Geller KS, Mendoza ID, Timbobolan J, Montjoy HL, Nigg CR. The Decisional Balance Sheet to Promote Healthy Behavior Among Ethnically Diverse Older Adults. Public Health Nurs. 2012; 29(3):241-246. doi:10.1111/j.1525-1446.2011.00987.x.

52. Jordan PJ, Nigg CR, Normal GJ, Rossi JS, Benisovich SV. Does the transtheoretical model need an attitude adjustment?: Integrating attitude with decisional balance as predictors of stage of change for exercise. Psychol Sport Exerc. 2002; 3(1):65-83.

53. Pinto BM, Clark MM, Cruess DG, Szymanski L, Pera V. Changes in self-efficacy and decisional balance for exercise among obese women in a weight management program. Obes Res. 1999; 7(3): 288-292. 
54. Oettingen G, Mayer D, Timur Sevincer A, Stephens EJ, Pak H, Hagenah M. Mental contrasting and goal commitment: The mediating role of energization. Pers Soc Psychol Bull. 2009; 35(5):608-622.

55. Duckworth AL, Grant H, Loew B, Oettingen G \& Gollwitzer PM. Self-regulation strategies improve self-discipline in adolescents: benefits of mental contrasting and implementation intentions. Educ Psychol. 2011; 31(1):17-26.

56. Reilly JJ, Penpraze V, Hislop J, Davies G, Grant S. Objective measurement of physical activity and sedentary behaviour: review with new data. Arch Dis Child. 2008; 93(7): 614-9.

This article is protected by copyright. All rights reserved. 


\section{Appendix 1: MEDLINE search strategy}

\#1 Chronic lung disease.mp.

\#2 *Lung Diseases/

\#3 Chronic Lung condition.mp.

\#4 Chronic pulmonary disease.mp.

\#5 Chronic heart disease.mp.

\#6 *Heart Diseases/

\#7 \#1 OR \#2 OR... \#6

\#8 Physical activit*.mp.

\#9 *Exercise Therapy/

\#10 Exercise.mp.

\#11 *Exercise/

\#12 Resistance training.mp.

\#13 *Resistance Training/

\#14 Aerobic training.mp.

\#15 Endurance training.mp.

\#16 * Physical Endurance/

\#17 \#8 OR \#9 OR \#10 OR... \#16

\#18 \#7 AND \#17

\#19 Limit \#18 to English language and humans

\#20 Limit \#19 to adolescents or young adults or adults

This article is protected by copyright. All rights reserved. 


\begin{tabular}{|c|c|c|c|c|c|c|}
\hline & Coelho (2017) [39] & Duppen (2015) [40] & Hebestreit (2010) [38] & Kriemler (2013) [41] & Morrison (2013) [42] & Scott (2013) [43] \\
\hline Inclusion criteria & $\begin{array}{l}18 \text { to } 65 \text { years of age, } \\
\text { asthma diagnosis for }> \\
6 \text { months, under } \\
\text { regular drug therapy } \\
\text { with at least moderate } \\
\text { doses of inhaled } \\
\text { corticosteroids (daily } \\
\text { dose }>400 \text { of } \\
\text { budesonide) or with } \\
\text { inhaled corticosteroids } \\
\text { plus long-acting beta }- \\
\text { agonsts and clinical } \\
\text { stability during the run } \\
\text { in period of the study. }\end{array}$ & $\begin{array}{l}\text { Tetralogy of Fallot } \\
\text { (ToF) or Fontan } \\
\text { patients } 10 \text { to } 25 \text { years } \\
\text { of age, correction of } \\
\text { ToF or Fontan } \\
\text { procedure performed } \\
\text { before } 3.5 \text { years and } 6 \\
\text { years, respectively, } \\
\text { mentally and } \\
\text { physically able to } \\
\text { adhere to a training } \\
\text { program. }\end{array}$ & $\begin{array}{l}\text { People with cystic } \\
\text { fibrosis (CF) } \\
\text { (diagnosis confirmed } \\
\text { with clinical picture, } \\
\text { positive sweat tests } \\
\text { and genotyping) Aged } \\
12 \text { years or older, } \\
\text { forced expiratory } \\
\text { volume in } 1 \text { second } \\
\text { (FEV } \text { F }_{1} \text { equal to or } \\
\text { greater than } 35 \% \\
\text { predicted and ability to } \\
\text { perform physical } \\
\text { activity. }\end{array}$ & $\begin{array}{l}\text { A diagnosis of CF, } \\
\text { aged } 12 \text { years or older } \\
\text { FEV } 135 \% \text { predicted } \\
\text { or higher and ability to } \\
\text { perform physical } \\
\text { activity without harm. }\end{array}$ & $\begin{array}{c}\text { Participants aged } 12 \text { to } \\
20 \text { years. }\end{array}$ & $\begin{array}{c}\text { Overweight and obese } \\
\text { (body mass index } 28 \\
\text { to 40), non-smokers, } \\
\text { adults (age not } \\
\text { defined). }\end{array}$ \\
\hline Exclusion criteria & $\begin{array}{l}\text { Self-reported exercise } \\
\text { of any intensity and } \\
\text { duration over once a }\end{array}$ & $\begin{array}{c}\text { Ventricular outflow } \\
\text { obstruction }>60 \\
\text { mmHg }\end{array}$ & $\begin{array}{l}\text { Non-CF or CF-related } \\
\text { chronic conditions } \\
\text { posing an increased }\end{array}$ & $\begin{array}{l}\text { Non-CF related } \\
\text { chronic disease and } \\
\text { conditions posing a }\end{array}$ & $\begin{array}{l}\text { Syndromic diagnosis, } \\
\text { major learning } \\
\text { difficulty or other }\end{array}$ & $\begin{array}{l}\text { Weight change }>5 \% \\
\text { in the preceding } 3 \\
\text { months, pregnancy or }\end{array}$ \\
\hline
\end{tabular}




\begin{tabular}{|c|c|c|c|c|c|c|}
\hline & $\begin{array}{c}\text { week, disabling } \\
\text { musculoskeletal } \\
\text { disease, 'cardiopathy', } \\
\text { 'coronariopathy', other } \\
\text { lung diseases, > 10 } \\
\text { pack-year smoking } \\
\text { history, illiteracy, } \\
\text { pregnancy or refusal to } \\
\text { participate. }\end{array}$ & $\begin{array}{l}\text { Contraindications to } \\
\text { cardiac magnetic } \\
\text { resonance imaging. }\end{array}$ & $\begin{array}{l}\text { risk to patients when } \\
\text { exercising (i.e. } \\
\text { oesophageal varicose, } \\
\text { pulmonary bullae, a < } \\
80 \% \text { drop in arterial } \\
\text { oxygen saturation } \\
\text { when exercising and } \\
\text { signs of pulmonary } \\
\text { hypertension on } \\
\text { electrocardiogram and } \\
\text { or echocardiogram). }\end{array}$ & $\begin{array}{l}\text { risk to the patient } \\
\text { when exercising. }\end{array}$ & $\begin{array}{l}\text { contraindication to } \\
\text { exercise. }\end{array}$ & $\begin{array}{l}\text { breastfeeding, cardiac } \\
\text { arrhythmia or angina, } \\
\text { renal or hepatic } \\
\text { failure, use of insulin } \\
\text { or oral hypoglycaemic } \\
\text { medication, gallstones, } \\
\text { pancreatitis, cancer or } \\
\text { an orthopaedic } \\
\text { problem that would } \\
\text { impede physical } \\
\text { activity. }\end{array}$ \\
\hline Number of groups & 2 & 2 & 2 & 3 & 2 & 3 \\
\hline $\begin{array}{c}\text { Group balance at } \\
\text { baseline }\end{array}$ & $\begin{array}{l}\text { Groups appeared to be } \\
\text { balanced at baseline. } \\
\text { However, it is possible } \\
\text { that a clinically } \\
\text { relevant difference } \\
\text { between the two } \\
\text { groups occurred } \\
\text { regarding body mass } \\
\text { index. }\end{array}$ & $\begin{array}{l}\text { Groups appeared to be } \\
\text { balanced at baseline. }\end{array}$ & $\begin{array}{l}\text { Groups appeared to be } \\
\text { balanced at baseline. }\end{array}$ & $\begin{array}{l}\text { Groups appeared to be } \\
\text { balanced at baseline. }\end{array}$ & $\begin{array}{l}\text { Groups appeared to be } \\
\text { balanced at baseline. }\end{array}$ & $\begin{array}{l}\text { Groups appeared to be } \\
\text { balanced at baseline. }\end{array}$ \\
\hline Sample size & $\begin{array}{l}\text { Estimated n = 30 to } \\
\text { detect increase of } 2491 \\
\text { steps (SD of } 2369 \\
\text { steps) with } 80 \% \text { power } \\
\text { and a two-sided alpha } \\
\text { level of } 0.05 \text {. Actual }\end{array}$ & $\begin{array}{l}\text { Estimated } \mathrm{n}=90 \text { to } \\
\text { detect an increase in } \\
\mathrm{VO}_{\text {2peak }} \text { of } 20 \text {, with } \\
88 \% \text { power and a two- } \\
\text { sided alpha of } 0.05 \text {. } \\
\text { Actual sample was } \mathrm{n}=\end{array}$ & $\begin{array}{c}\text { Sample size } \\
\text { calculation provided in } \\
\text { online supplement. } \\
\text { Sample size } \\
\text { calculation based on } \\
\text { an increase in the peak }\end{array}$ & $\begin{array}{c}\text { Sample size } \\
\text { calculation provided in } \\
\text { online supplement. } \\
\text { Estimated } n=20 \text { per } \\
\text { arm with } 80 \% \text { power } \\
\text { and alpha of } 0.05 \text { for }\end{array}$ & $\begin{array}{c}\mathrm{n}=143 \text { randomised. } \\
\text { Sample size } \\
\text { calculation not stated } \\
\text { in data analysis } \\
\text { section. Study } \\
\text { limitations highlight }\end{array}$ & $\begin{array}{l}\mathrm{n}=46 \text { were } \\
\text { randomised, } \mathrm{n}=38 \\
\text { completed the trial. } \\
\text { Underpowered to } \\
\text { detect change - } \\
\text { discussed in }\end{array}$ \\
\hline
\end{tabular}




\begin{tabular}{|c|c|c|c|c|c|c|}
\hline 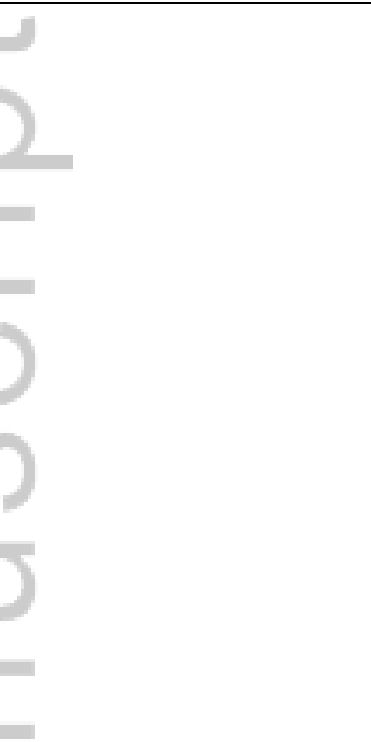 & $\begin{array}{c}\text { sample size was } \mathrm{n}= \\
37, \text { and } \mathrm{n}=30 \\
\text { completed the } \\
\text { intervention. }\end{array}$ & $\begin{array}{l}93 \text { and } 90 \text { were } \\
\text { analysed. }\end{array}$ & $\begin{array}{l}\text { rate of oxygen uptake } \\
\text { (VO } \mathrm{V}_{2 \text { peak }} \text { of at least } 1 \\
\mathrm{SD} \text { over the control } \\
\text { group, with a power of } \\
80 \% \text { and two-sided } \\
\text { alpha of } 0.05 \text { and } 60 \% \\
\text { allocation to the } \\
\text { intervention group. } \\
\text { Required } \mathrm{n}=21 \text { in the } \\
\text { intervention group and } \\
\mathrm{n}=14 \text { in the control } \\
\text { group. Planned to } \\
\text { recruit } \mathrm{n}=38 \text {. } \\
\text { Randomised } \mathrm{n}=38 \text {, } \\
\text { and } \mathrm{n}=28 \text { completed } \\
\text { final follow-up. }\end{array}$ & $\begin{array}{l}\text { an effect of } 0.43 \text { times } \\
\text { the } S D \text { with the } \\
\text { primary outcome } \\
\text { being } \mathrm{FEV}_{1} \text {, although } \\
\text { this is not explicitly } \\
\text { stated in the sample } \\
\text { size calculation. }\end{array}$ & $\begin{array}{l}\text { that } \mathrm{n}=143 \text { is } \mathrm{n}=37 \\
\text { less than anticipated. }\end{array}$ & $\begin{array}{l}\text { limitations section. } \\
\text { Actual sample size } \\
\text { calculation not } \\
\text { provided. }\end{array}$ \\
\hline $\begin{array}{c}\text { Assessment time } \\
\text { points }\end{array}$ & $\begin{array}{c}\text { Baseline, post } \\
\text { intervention (12 } \\
\text { weeks), } 24 \text { to } 28 \\
\text { weeks post } \\
\text { randomisation. }\end{array}$ & $\begin{array}{l}\text { Baseline and post } \\
\text { intervention (12 } \\
\text { weeks). }\end{array}$ & $\begin{array}{c}\text { Baseline, and after } 3 \text {, } \\
\text { 6, 12, } 18 \text { and } 24 \\
\text { months. }\end{array}$ & $\begin{array}{c}\text { Baseline and after 3, 6, } \\
12 \text { and } 24 \text { months. }\end{array}$ & $\begin{array}{l}\text { Baseline and } 6 \\
\text { months. }\end{array}$ & $\begin{array}{c}\text { Baseline, week } 10 \text { and } \\
\text { week } 20 .\end{array}$ \\
\hline Primary outcome(s) & Step count & $\mathrm{VO}_{2 \text { peak }}$ & $\mathrm{VO}_{2 \text { peak }}$ & $\mathrm{FEV}_{1}$ & $\begin{array}{l}\text { Increase in exercise } \\
\text { capacity and time } \\
\text { spent in moderate to } \\
\text { vigorous physical } \\
\text { activity (MVPA). }\end{array}$ & $\begin{array}{l}\text { Unclear. Listed as } \\
\text { expiratory reserve } \\
\text { volume, quality of life } \\
\text { on study registry. }\end{array}$ \\
\hline
\end{tabular}




\begin{tabular}{|c|c|c|c|c|c|}
\hline & $\begin{array}{c}\text { Asthma control, } \\
\text { health-related quality } \\
\text { of life, anxiety, } \\
\text { depression, 6 minute } \\
\text { outcome(s) }\end{array}$ & $\begin{array}{c}\text { Time spent in MVPA } \\
\text { walk test. }\end{array}$ & $\begin{array}{c}\text { Vigorous physical } \\
\text { activity (hours per } \\
\text { week). }\end{array}$ & $\begin{array}{c}\text { MVPA (hours per } \\
\text { week). }\end{array}$ & International Physical \\
Activity \\
Questionnaire, which \\
included steps per day.
\end{tabular}

Abbreviations: CF: cystic fibrosis. $\mathrm{FEV}_{1}$ : forced expiratory volume in 1 second. MVPA: moderate to vigorous physical activity. ToF: Tetralogy of Fallot. VO${ }_{2 p e a k}$ : peak rate of oxygen uptake. 


\section{University Library}

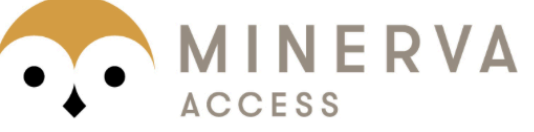

A gateway to Melbourne's research publications

Minerva Access is the Institutional Repository of The University of Melbourne

Author/s:

Sawyer, A;Lewthwaite, H;Gucciardi, DF;Hill, K;Jenkins, S;Cavalheri, V

Title:

Behaviour change techniques to optimise participation in physical activity or exercise in adolescents and young adults with chronic cardiorespiratory conditions: a systematic review

Date:

2019-10-01

\section{Citation:}

Sawyer, A., Lewthwaite, H., Gucciardi, D. F., Hill, K., Jenkins, S. \& Cavalheri, V. (2019). Behaviour change techniques to optimise participation in physical activity or exercise in adolescents and young adults with chronic cardiorespiratory conditions: a systematic review. INTERNAL MEDICINE JOURNAL, 49 (10), pp.1209-1220. https://doi.org/10.1111/ imj. 14141.

Persistent Link:

http://hdl.handle.net/11343/286452 